\title{
Mixed Phases at the Bottom Interface of Si-Doped AlGaN Epilayers of Optoelectronic Devices
}

\author{
Chen-hui Yu, ${ }^{1}$ Qing-zhou Luo, ${ }^{2}$ Xiang-dong Luo, ${ }^{1}$ and Pei-sheng Liu ${ }^{1}$ \\ ${ }^{1}$ Jiangsu Key Laboratory of ASIC Design, Nantong University, Nantong 226019, China \\ ${ }^{2}$ School of Remote Sensing, Nanjing University of Information Science and Technology, Nanjing 210044, China \\ Correspondence should be addressed to Chen-hui Yu; ychntu@126.com
}

Received 17 December 2013; Accepted 7 January 2014; Published 13 February 2014

Academic Editor: Wen Lei

Copyright (c) 2014 Chen-hui Yu et al. This is an open access article distributed under the Creative Commons Attribution License, which permits unrestricted use, distribution, and reproduction in any medium, provided the original work is properly cited.

\begin{abstract}
This paper presents an analysis of crystalline structures of Si-doped $\mathrm{Al}_{0.4} \mathrm{Ga}_{0.6} \mathrm{~N}$ layers grown on not-intentionally doped AlGaN buffer layer with an AlN nucleation layer by metal organic chemical vapor deposition. Weak cubic $\mathrm{Al}_{0.4} \mathrm{Ga}_{0.6} \mathrm{~N}(002)$ and (103) reflection peaks are observed in high-resolution XRD $\theta / 2 \theta$ scans and cubic $\mathrm{Al}_{0.4} \mathrm{Ga}_{0.6} \mathrm{~N}$ (LO) mode in Raman scattering spectroscopy. These cubic subgrains are localized at the bottom interface of Si-doped layer due to the pulsed lower growth temperature and rich hydrogen atmosphere at the start of silane injection. Their appearance has no direct relationship with the buffer and nucleation layer. This study is helpful not only to understand fundamental properties of high aluminum content Sidoped AlGaN alloys but also to provide specific guidance on the fabrication of multilayer optoelectronic devices where weak cubic subgrains potentially occur and exert complicated influences on the device performance.
\end{abstract}

\section{Introduction}

GaN and its alloys (e.g., AlGaN, InAlN, and InGaN) are foundations for new optoelectronic devices such as blue/violet light-emitting diode (LED), high electron mobility transistor (HEMT), ultraviolet and/or infrared photodetectors, and plasmonic Terahertz detectors [1-7]. GaN usually exists in either a hexagonal wurtzite $(h)$ or a cubic zinc blende $(c)$ structure $[1,2,8,9]$. Devices based on the two crystalline structures show very different optical and electrical performances. The emitting peak or optical response wavelength is different for the different bandgap energy $E_{g}$ of $c$-GaN and $h$-GaN. The mobility of electrons and holes in a $c-\mathrm{GaN}$ film is intrinsically higher than that in a $h$-GaN layer due to lower phonon scattering in cubic crystals [8]. However, more electron and hole traps may appear in film with a mixture of $c$ - and $h$-GaN for the stacking faults among the two kinds of crystalline subgrains [10]. The coexistence of the two crystalline structures in a single film is possible for the proximity of their formation energies. Therefore, it is of great importance to understand and control the occurrence of these crystalline structures. Previous works have demonstrated that, in not-intentionally doped (NID)
GaN layers, an obvious lower substrate temperature is necessary to obtain a pure cubic phase rather than that of a pure hexagonal phase by metal organic chemical vapor deposition (MOCVD) or molecular-beam epitaxy (MBE) $[8,11-13]$. Recently, uniformly distributed $c-\mathrm{GaN}$ and $h$ GaN subgrains have been simultaneously found in NID $\mathrm{GaN}$ nucleation layers grown on sapphire substrate. Both subgrains provide templates for the subsequent epitaxial growth, having important influence on the crystalline quality of $\mathrm{GaN}[9,12,14]$. However, few studies have examined the possible mixed crystalline structures in doped AlGaN alloys with high aluminum content.

In the present work, we report simultaneous observations of cubic and hexagonal subgrains in a group of silicon doped (Si-doped) AlGaN epilayers. We have designed and grown those Si-doped $\mathrm{Al}_{0.4} \mathrm{Ga}_{0.6} \mathrm{~N}$ samples by MOCVD. Highresolution X-ray diffraction (XRD) and Raman spectroscopy are employed to analyze their crystalline structures. The possible reasons for the occurrence of weak cubic subgrains in the epilayers are discussed. Our experimental results are quite different from previous work in that the coexistence of cubic and hexagonal subgrains occurs in a group of $\mathrm{Si}$ doped $\mathrm{Al}_{0.4} \mathrm{Ga}_{0.6} \mathrm{~N}$ epilayers. Moreover, the cubic subgrains 


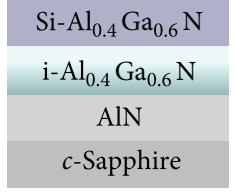

(A)

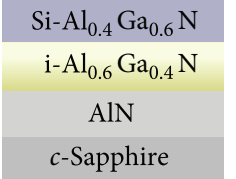

(B)

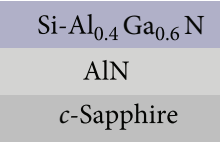

(C)
Figure 1: Schematic diagram of samples A, B, and C.

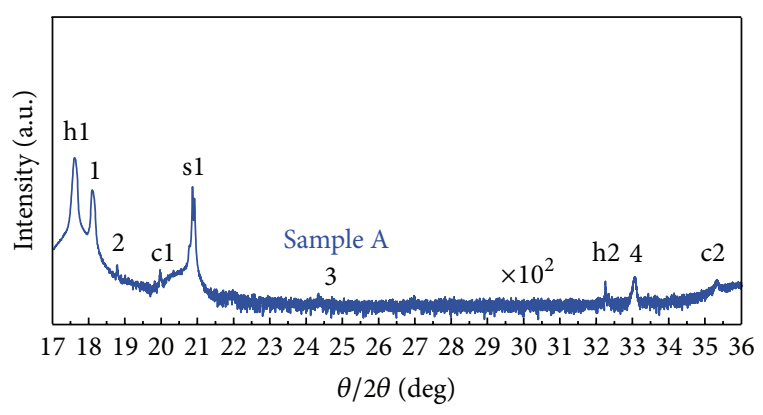
(h1) $\mathrm{Al}_{0.4} \mathrm{Ga}_{0.6} \mathrm{~N}(002)$
(h2) $\mathrm{Al}_{0.4} \mathrm{Ga}_{0.6} \mathrm{~N}(103)$
(s1) $\mathrm{Al}_{2} \mathrm{O}_{3}(006)$
(1) $\mathrm{AlN}(002)$
(2) $\operatorname{AlN}(101)$
(3) $\operatorname{AlN}(102)$
(4) $\operatorname{AlN}(103)$
(c1) $c-\mathrm{Al}_{0.4} \mathrm{Ga}_{0.6} \mathrm{~N}(002)$
(c2) $c-\mathrm{Al}_{0.4} \mathrm{Ga}_{0.6} \mathrm{~N}(113)$

Figure 2: XRD $\theta / 2 \theta$ patterns of Si-doped $\mathrm{Al}_{0.4} \mathrm{Ga}_{0.6} \mathrm{~N}$ epilayer, sample A, from $17^{\circ}$ to $36^{\circ}$.

observed are locally distributed at the bottom interface of epilayers. These results are meaningful to the growth and understanding of multiple-interface GaN-based optoelectronic devices such as quantum well photodetectors and LEDs.

\section{Experimental}

Samples studied in this work were grown at a low pressure by an in-house developed MOCVD system. The geometric structure of sample $A$ was Si-doped $\mathrm{Al}_{0.4} \mathrm{Ga}_{0.6} \mathrm{~N} / \mathrm{NID}$ $\mathrm{Al}_{0.4} \mathrm{Ga}_{0.6} \mathrm{~N}$ (buffer layer)/AlN (nucleation layer) on a sapphire substrate as shown in Figure 1. The AlN nucleation layer was a bilayer structure with its first layer grown at a low temperature of about $750^{\circ} \mathrm{C}$ to initiate nucleation, followed by a second layer at a high temperature of about $1050^{\circ} \mathrm{C}$ to achieve 2D growth. The NID $\mathrm{Al}_{0.4} \mathrm{Ga}_{0.6} \mathrm{~N}$ buffer layer and Si-doped $\mathrm{Al}_{0.4} \mathrm{Ga}_{0.6} \mathrm{~N}$ layer were prepared at a temperature of about $1000^{\circ} \mathrm{C}$. Two control samples, B and $\mathrm{C}$, were also prepared for comparison and analysis. The geometric structures of $\mathrm{B}$ and $\mathrm{C}$ were almost the same as $\mathrm{A}$ except that the buffer layer of $\mathrm{B}$ was a NID $\mathrm{Al}_{0.6} \mathrm{Ga}_{0.4} \mathrm{~N}$ layer instead and $\mathrm{C}$ had no buffer layer at all. All samples were crack-free showing good crystalline qualities.

XRD measurements, with $\mathrm{Cu} \operatorname{K} \alpha 1(\lambda=1.54056 \AA)$ as a source, were performed to analyze dislocations, crystalline phase, subgrain orientation, and so forth. The room temperature Raman scattering spectra were obtained using a LabRam HR800UV Raman spectrometer (Horiba JobinYvon) fitted with a confocal microscope and a cooled chargecoupled device (CCD) detector. Samples were excited with the $514.5 \mathrm{~nm}$ green line of a Spectra Physics $\mathrm{Ar}^{+}$laser focused under a microscope within a diameter of the analyzed spot around $1.0 \mu \mathrm{m}$. Raman scattering is a noncontact and nondestructive spectroscopic technology $[9,12,15]$. Raman spectroscopy and XRD measurements have been used together to investigate the crystalline structures in GaN-based thin film heterostructures comprehensively.

\section{Results and Discussion}

A high-resolution XRD $\theta / 2 \theta$ scan of sample A is shown in Figure 2. During the measurement, the power of the X-ray generator in the range from $17^{\circ}$ to $23^{\circ}$ remained at $40 \mathrm{kV}$ and $10 \mathrm{~mA}$ but was increased to $40 \mathrm{kV}$ and $40 \mathrm{~mA}$ in other ranges. Though this power increase induced a slight noise variance, it was helpful for the effective detection of much weaker reflected signals. Besides the strong $\mathrm{Al}_{2} \mathrm{O}_{3}$ (006) peak at around $20.80^{\circ}$ from sapphire substrate, other reflection peaks could be grouped into three series $[16,17]$. The first series are (002), (101), (102), and (103) reflection peaks from the hexagonal AlN nucleation layer. The second series are (002) and (103) peaks from the hexagonal $\mathrm{Al}_{0.4} \mathrm{Ga}_{0.6} \mathrm{~N}$ layers. This indicates the dominant role of the hexagonal crystalline structure in the samples.

Two much weaker peaks at about $19.9^{\circ}$ and $35.3^{\circ}$ are observed as shown in Figure 3. They are obviously different from any possible reflections from AlN, GaN, substrate and hexagonal $\mathrm{Al}_{0.4} \mathrm{Ga}_{0.6} \mathrm{~N}$, even when the considerable stress effect and experimental errors are taken into account. These remaining peaks have little possibility to be satellite peaks either. Satellite peaks usually occur as continuous oscillating structures and multiorder peaks should be observed simultaneously. By comparing with previous works on pure cubic and mixed-phase GaN-based alloys, we attribute these two peaks to the cubic $\mathrm{Al}_{0.4} \mathrm{Ga}_{0.6} \mathrm{~N}$ (002) and (113) reflection, respectively, which are indeed the two most intense signals in XRD measurement on cubic GaN-based alloys [11, 18, 19]. The cubic $\mathrm{Al}_{0.4} \mathrm{Ga}_{0.6} \mathrm{~N}$ (002) and (113) reflection peaks have also been observed in control samples $\mathrm{B}$ and $\mathrm{C}$. In summary, both hexagonal and weak cubic $\mathrm{Al}_{0.4} \mathrm{Ga}_{0.6} \mathrm{~N}$ subgrains coexist in these epilayers.

The Raman spectra of Si-doped $\mathrm{Al}_{0.4} \mathrm{Ga}_{0.6} \mathrm{~N}$ films shown in Figure 4 were recorded in a back-scattering configuration from the growth surface with a laser beam propagating parallel to the $c$ axis of substrate. The inset shows the whole Raman spectra of sample A from $220 \mathrm{~cm}^{-1}$ to $980 \mathrm{~cm}^{-1}$. Several peaks labeled with $S$ originating from the sapphire substrate are observed at about $751 \mathrm{~cm}^{-1}$ and in the region from $380 \mathrm{~cm}^{-1}$ to $450 \mathrm{~cm}^{-1}$ [12]. Hexagonal AlN E (low), AlN $E_{2}$ (high), and AlN $A_{1}$ (LO) modes are also observed at $249 \mathrm{~cm}^{-1}, 751 \mathrm{~cm}^{-1}$, and $886 \mathrm{~cm}^{-1}$, respectively $[15,20]$. The intense peak at $582 \mathrm{~cm}^{-1}$ is an overlapped structure with broad width including signals from sapphire, $h$-AlGaN $E_{2}$ (high) mode, and so forth. The active $h-\mathrm{Al}_{0.4} \mathrm{Ga}_{0.6} \mathrm{~N}$ (LO) mode appears at $822 \mathrm{~cm}^{-1}$. These features show the dominant 


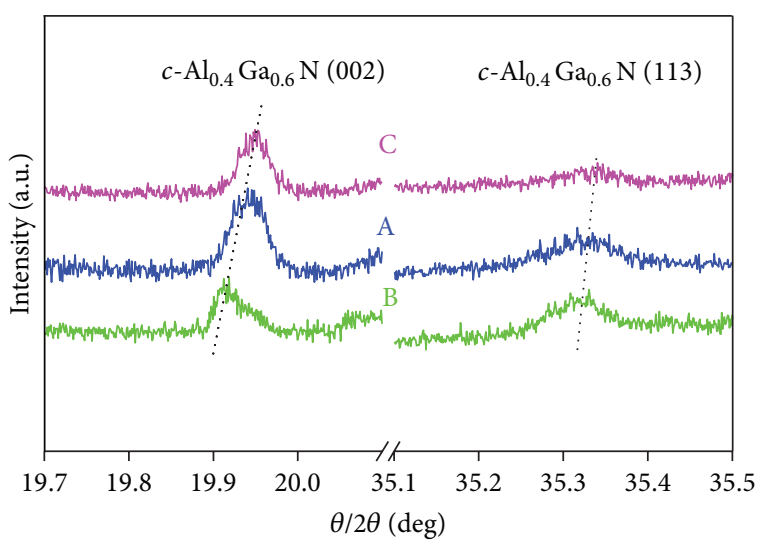

FIgure 3: Comparison of XRD $\theta / 2 \theta$ patterns of sample A and control samples $\mathrm{B}$ and $\mathrm{C}$. Cubic $\mathrm{Al}_{0.4} \mathrm{Ga}_{0.6} \mathrm{~N}$ (002) and (103) reflection peaks are clearly observed. Dotted lines are used for visual aid.

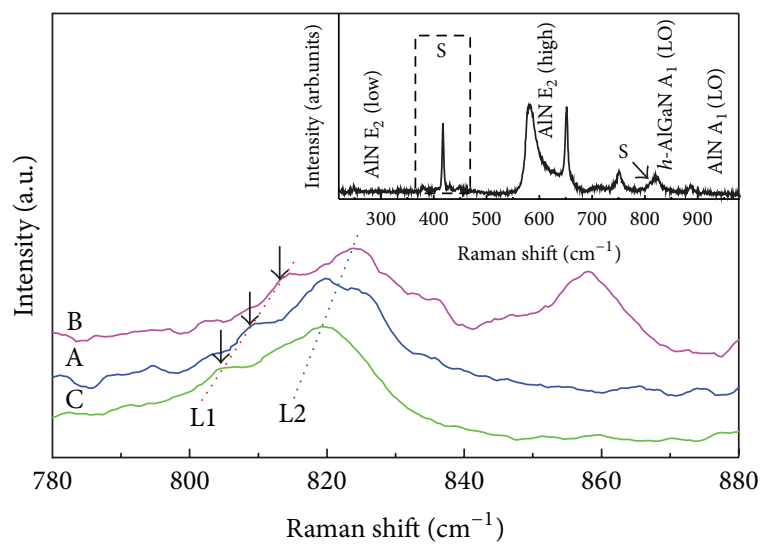

FIgURE 4: Raman spectra of $\mathrm{Si}$-doped $\mathrm{Al}_{0.4} \mathrm{Ga}_{0.6} \mathrm{~N}$ epilayers. Inset is Raman spectra of sample A from $220 \mathrm{~cm}^{-1}$ to $980 \mathrm{~cm}^{-1}$. Dotted lines $\mathrm{L} 1$ and $\mathrm{L} 2$ are used for visual aid. Cubic $\mathrm{Al}_{0.4} \mathrm{Ga}_{0.6} \mathrm{~N}$ (LO) modes are observed.

role of hexagonal crystalline structure in these epilayers. Meanwhile, a weak shoulder (L1) to lower wave number side of $h-\mathrm{Al}_{0.4} \mathrm{Ga}_{0.6} \mathrm{~N}$ (LO) mode (L2) is also clearly resolved at about $810 \mathrm{~cm}^{-1}$. This weak shoulder, also reported in earlier studies, is attributed to the $c-\mathrm{Al}_{0.4} \mathrm{Ga}_{0.6} \mathrm{~N}(\mathrm{LO})$ mode $[13,21]$. In most cases, the $c$-AlGaN (TO) mode, which is nominally forbidden but becomes allowed due to any short range perturbations, should be detected simultaneously as the LO mode. In this study, no $c-\mathrm{Al}_{0.4} \mathrm{Ga}_{0.6} \mathrm{~N}$ (TO) mode was found in the Raman spectra. This discrepancy is due to two factors: (i) the otherwise $c-\mathrm{Al}_{0.4} \mathrm{Ga}_{0.6} \mathrm{~N}$ (TO) mode at about $606 \mathrm{~cm}^{-1}$ couples strongly with the intense and broad peak at $582 \mathrm{~cm}^{-1}$ and (ii) the TO mode of cubic phase is fairly weak under the excitation with a $514.5 \mathrm{~nm}$ laser line [21]. The $c-\mathrm{Al}_{0.4} \mathrm{Ga}_{0.6} \mathrm{~N}$ (LO) modes have been also observed in the Raman spectra of control samples B and C, shown in Figure 4. The results of Raman and XRD measurements are in good agreement and confirm the coexistence of hexagonal and weak cubic subgrains in the Si-doped $\mathrm{Al}_{0.4} \mathrm{Ga}_{0.6} \mathrm{~N}$ epilayers.

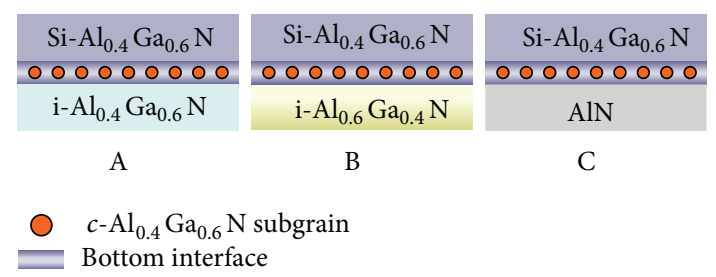

FIgURE 5: Distribution of cubic $\mathrm{Al}_{0.4} \mathrm{Ga}_{0.6} \mathrm{~N}$ subgrains at the bottom interface of Si-doped epilayers.

The favored growth conditions for hexagonal wurtzite and cubic zinc blende structures in MOCVD epitaxy are considerably different. The coexistence of hexagonal and cubic GaN-based alloys could only be found in special environments. For example, a frequently mentioned film is GaN nucleation layers deposited at a low temperature of about $600^{\circ} \mathrm{C}[9,12]$. In our case, an AlN nucleation layer instead is adopted and no cubic AlN subgrains have been detected by either XRD or Raman measurements. Then, an interesting question is raised as to where the cubic $\mathrm{Al}_{0.4} \mathrm{Ga}_{0.6} \mathrm{~N}$ subgrains are located. We could find answers through a layer-by-layer analysis. Firstly, both the sapphire substrate and the AlN nucleation layers have no relationship with the occurrence of cubic $\mathrm{Al}_{0.4} \mathrm{Ga}_{0.6} \mathrm{~N}$ subgrains. Secondly, cubic subgrains are independent of the $\mathrm{Al}_{0.4} \mathrm{Ga}_{0.6} \mathrm{~N}$ buffer layer. The hexagonal $\mathrm{Al}_{0.4} \mathrm{Ga}_{0.6} \mathrm{~N}$ buffer layer is grown solely in sample $\mathrm{A}$. The buffer layer in sample $\mathrm{B}$ is replaced with an $h$ - $\mathrm{Al}_{0.6} \mathrm{Ga}_{0.4} \mathrm{~N}$ layer. In sample $\mathrm{C}$, no buffer layer is prepared at all. In spite of this diversity, characteristic features from cubic $\mathrm{Al}_{0.4} \mathrm{Ga}_{0.6} \mathrm{~N}$ subgrains have been observed in all the three samples. Then, we could claim that the occurrence of cubic $\mathrm{Al}_{0.6} \mathrm{Ga}_{0.4} \mathrm{~N}$ has no correlation with the buffer layer. In fact, we did perform measurements on single $\mathrm{Al}_{0.4} \mathrm{Ga}_{0.6} \mathrm{~N}$ buffer layer grown on AlN buffer layer and no characteristic features of cubic subgrains have been observed in either XRD or Raman measurements. Earlier literatures also indicate that there is little chance to find cubic subgrains in NID AlGaN epilayers grown under similar epitaxy conditions as this work [22]. Thus, the occurrence of cubic $\mathrm{Al}_{0.6} \mathrm{Ga}_{0.4} \mathrm{~N}$ subgrains is undoubtedly related to the growth of Si-doped $\mathrm{Al}_{0.4} \mathrm{Ga}_{0.6} \mathrm{~N}$ layers.

These cubic subgrains have two possible existing forms in films. The first one is an even distribution. However, characteristic features from cubic subgrains in our Si-doped $\mathrm{Al}_{0.4} \mathrm{Ga}_{0.6} \mathrm{~N}$ layer are particularly weak in both XRD and Raman measurements. In addition, few researchers, including us, have reported cubic signals in thick Si-doped AlGaN layers grown at a high temperature of about $1000^{\circ} \mathrm{C}$. Then, the possibility of uniform distribution could be excluded. The second form is a local distribution at the bottom interface between buffer layer and the Si-doped layer as shown in Figure 5. This situation could be understood from the point of view of growth environments. Previous works indicate that a higher growth temperature and a rich nitrogen atmosphere favor the growth of hexagonal GaN-based alloys, while a lower growth temperature and a rich hydrogen atmosphere are beneficial to the occurrence of cubic subgrains [8]. 
At the onset of doping, silane (doping agent) carried by high room temperature hydrogen fluxes was instantaneously injected into the reaction chamber of in-house developed MOCVD, leading to a quick decrease of reaction temperature and a relatively high percentage of nitrogen atmosphere, and subsequently results in the occurrence of weak cubic subgrains. With the increase in processing time, the reaction temperature and atmosphere recover and the pure hexagonal crystalline phase becomes the sole structure again. This is why the cubic subgrains occur locally at the bottom interface of Si-doped layers. Meanwhile, interstitial silicon atoms in the Si-doped layers increase the deformation of the hexagonal crystalline lattice and cubic structure in GaN-based alloys resulting in a deformed hexagonal lattice with stacking faults in alternative layers [9]. Then, the interstitial silicon atoms are the possible reason for the occurrence of cubic subgrains. The morphology and microstructure of these weak cubic subgrains at the interface will be considered in further works.

\section{Summary and Conclusions}

In summary, we have investigated the crystalline structures of Si-doped $\mathrm{Al}_{0.4} \mathrm{Ga}_{0.6} \mathrm{~N}$ layers grown with an AlN nucleation layer by MOCVD. We have also observed cubic $\mathrm{Al}_{0.4} \mathrm{Ga}_{0.6} \mathrm{~N}$ (002) and (103) reflection peaks in high-resolution XRD $\theta / 2 \theta$ scans and cubic $\mathrm{Al}_{0.4} \mathrm{Ga}_{0.6} \mathrm{~N}$ (LO) mode in Raman scattering spectroscopy, as well as the specific features from hexagonal wurtzite structure of $\mathrm{Al}_{0.4} \mathrm{Ga}_{0.6} \mathrm{~N}$. It is found that the cubic subgrains are localized at the bottom interface of Si-doped layer due to the pulsed lower growth temperature and rich hydrogen atmosphere at the start of silane injection. This study is helpful not only to understand of fundamental properties of GaN-based alloys, but also to provide specific guidance on the growth of multilayer optoelectronic devices such as LED, HEMT, and quantum well photo-detector, where weak cubic subgrains potentially occur at the multiply interfaces and exert complicated influences on the device performances.

\section{Conflict of Interests}

All authors declare that there is no conflict of interests regarding the publication of this paper.

\section{Acknowledgments}

The authors thank James Torley from the University of Colorado at Colorado Springs for critical reading of the paper. This work was supported in part by the National Natural Science Foundation of China (Grant nos. 11104150, 11274330, and 41001288) and the Natural Science Foundation of Jiangsu Province of China (Grant no. 10KJA140043).

\section{References}

[1] Q. Y. Wei, T. Li, J. Y. Huang et al., "Free carrier accumulation at cubic AlGaN/GaN heterojunctions," Applied Physics Letters, vol. 100, no. 14, Article ID 142108, 2012.
[2] E. A. DeCuir Jr., M. O. Manasreh, E. Tschumak, J. Schörmann, D. J. As, and K. Lischka, "Cubic GaNAlN multiple quantum well photodetector," Applied Physics Letters, vol. 92, no. 20, Article ID 201910, 2008.

[3] W. D. Hu, X. S. Chen, Z. J. Quan, C. S. Xia, W. Lu, and H. J. Yuan, "Demonstration and dynamic analysis of trapping of hot electrons at gate edge model for current collapse and gate lag in GaN-based high-electron-mobility transistor including selfheating effect," Applied Physics Letters, vol. 89, no. 24, Article ID 243501, 2006.

[4] X. Wang, W. Hu, X. Chen, and W. Lu, "The study of selfheating and hot-electron effects for AlGaN/GaN doublechannel HEMTs," IEEE Transactions on Electron Devices, vol. 59, no. 5, pp. 1393-1401, 2012.

[5] N. Guo, W. D. Hu, X. S. Chen, L. Wang, and W. Lu, "Enhanced plasmonic resonant excitation in a grating gated field-effect transistor with supplemental gates," Optics Express, vol. 21, pp. 1606-1614, 2013.

[6] W. D. Hu, L. Wang, X. S. Chen et al., "Room-temperature plasmonic resonant absorption for grating-gate GaN HEMTs in far infrared terahertz domain," Optical and Quantum Electronics, vol. 45, pp. 713-720, 2013.

[7] C. H. Yu, Q. Z. Luo, X. D. Luo, and P. S. Liu, "Donor-like surface traps on two-dimensional electron gas and current collapse of AlGaN/GaN HEMTs," The Scientific World Journal, vol. 2013, Article ID 931980, 6 pages, 2013.

[8] B. M. Shi, M. H. Xie, H. S. Wu, N. Wang, and S. Y. Tong, "Transition between wurtzite and zinc-blende GaN: an effect of deposition condition of molecular-beam epitaxy," Applied Physics Letters, vol. 89, no. 15, Article ID 151921, 2006.

[9] J. Narayan, P. Pant, A. Chugh, H. Choi, and J. C. C. Fan, "Characteristics of nucleation layer and epitaxy in GaN/sapphire heterostructures," Journal of Applied Physics, vol. 99, no. 5, Article ID 054313, 2006.

[10] M. S. Yi, H. H. Lee, D. J. Kim et al., "Effects of growth temperature on GaN nucleation layers," Applied Physics Letters, vol. 75, no. 15, pp. 2187-2189, 1999.

[11] T. Frey, D. J. As, M. Bartels et al., "Structural and vibrational properties of molecular beam epitaxy grown cubic (Al, Ga)N/GaN heterostructures," Journal of Applied Physics, vol. 89, no. 5, pp. 2631-2634, 2001.

[12] A. Hushur, M. H. Manghnani, and J. Narayan, "Raman studies of GaN/sapphire thin film heterostructures," Journal of Applied Physics, vol. 106, no. 5, Article ID 054317, 2009.

[13] H. F. Liu, H. Chen, Z. Q. Li et al., "MBE growth and Raman studies of cubic and hexagonal GaN films on (001)-oriented GaAs substrates," Journal of Crystal Growth, vol. 218, no. 2, pp. 191-196, 2000.

[14] P. Pant, J. Narayan, A. Wushuer, and M. H. Manghnani, "Comparative Raman and HRTEM study of nanostructured GaN nucleation layers and device layers on sapphire (0001)," Journal of Nanoscience and Nanotechnology, vol. 8, no. 11, pp. 5985-5992, 2008.

[15] V. Lughi and D. R. Clarke, "Defect and stress characterization of AlN films by Raman spectroscopy," Applied Physics Letters, vol. 89, no. 24, Article ID 241911, 2006.

[16] J. Y. Li, X. L. Chen, Z. Y. Qiao, Y. G. Cao, M. He, and T. Xu, "Synthesis of aligned gallium nitride nanowire quasi-arrays," Applied Physics A, vol. 71, no. 3, pp. 349-350, 2000.

[17] A. Artieda, M. Barbieri, C. S. Sandu, and P. Muralt, "Effect of substrate roughness on c-oriented AlN thin films," Journal of Applied Physics, vol. 105, no. 2, Article ID 024504, 2009. 
[18] R. Armitage, K. Nishizono, J. Suda, and T. Kimoto, "Mechanism of stabilization of zincblende GaN on hexagonal substrates: insight gained from growth on ZrB2 (0001)," Journal of Crystal Growth, vol. 284, no. 3-4, pp. 369-378, 2005.

[19] X. H. Zheng, Y. T. Wang, Z. H. Feng et al., "Method for measurement of lattice parameter of cubic GaN layers on GaAs (001)," Journal of Crystal Growth, vol. 250, no. 3-4, pp. 345-348, 2003.

[20] V. Y. Davydov, Y. E. Kitaev, I. N. Goncharuk et al., "Phonon dispersion and Raman scattering in hexagonal GaN and AIN," Physical Review B, vol. 58, no. 19, pp. 12899-12907, 1998.

[21] A. Tabata, R. Enderlein, J. R. Leite et al., "Comparative Raman studies of cubic and hexagonal GaN epitaxial layers," Journal of Applied Physics, vol. 79, no. 8, pp. 4137-4140, 1996.

[22] F. A. Ponce, J. S. Major Jr., W. E. Plano, and D. F. Welch, "Crystalline structure of AlGaN epitaxy on sapphire using AlN buffer layers," Applied Physics Letters, vol. 65, no. 18, pp. 23022304, 1994. 

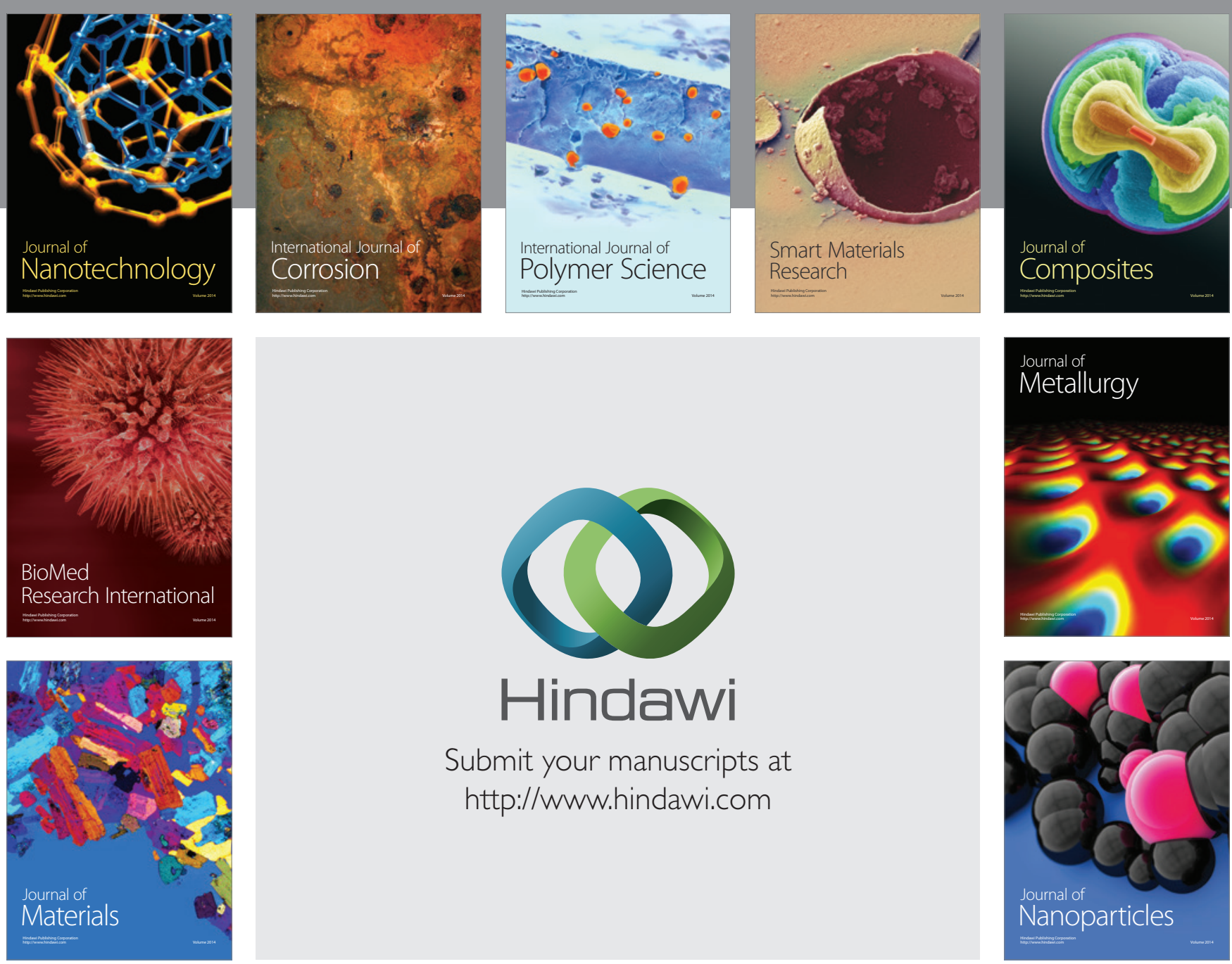

Submit your manuscripts at http://www.hindawi.com
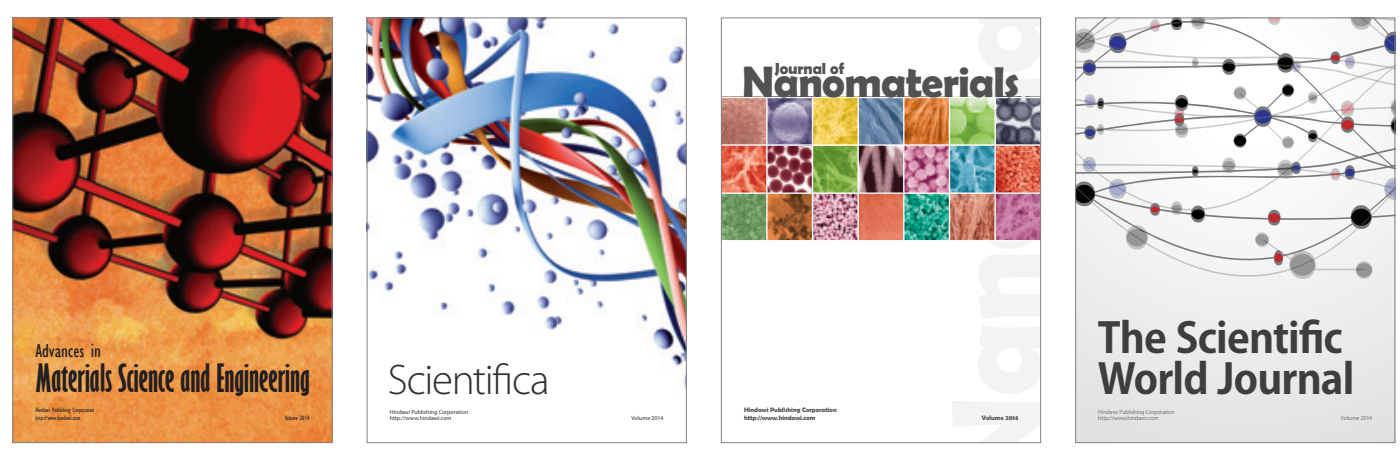

\section{The Scientific World Journal}
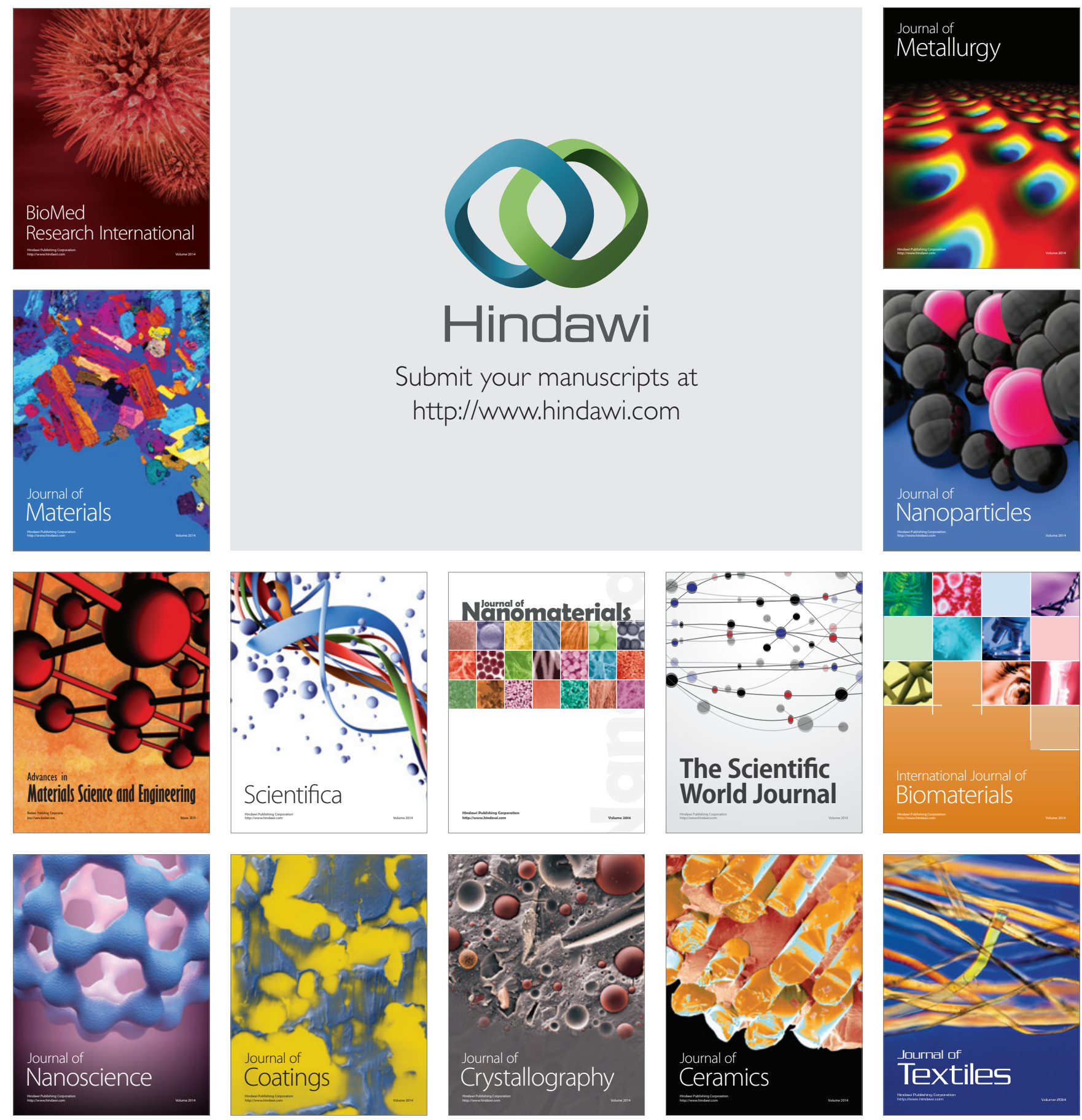